\title{
Clinical Study of Snakebite Cases Admitted in Dhaka Medical College Hospital
}

\author{
Prabal Chakraborty' \\ Jishu Deb Nath ${ }^{*}$ \\ MA Faiz' \\ Anannya Das ${ }^{3}$ \\ Abdul Qayum Chowdhury ${ }^{4}$
}

'Department of Medicine Dhaka Medical College Dhaka, Bangladesh.

${ }^{2}$ Department of Medicine Chattagram Maa-O-Shishu Hospital Medical College Chittagong, Bangladesh.

${ }^{3}$ Department of Medicine BGC Trust Medical College Chittagong, Bangladesh.

${ }^{4}$ Department of ENT

Chattagram Maa-O-Shishu Hospital Medical College Chittagong, Bangladesh.
*Correspondence to:

\section{Dr Jishu Deb Nath}

Assistant Professor

Department of Medicine

Chattagram Maa-Shishu-O-General Hospita

Agrabad, Chittagong

Bangladesh.

Mobile: +88-01716405056

E mail:jishudebnath2007@gmail.com

\begin{abstract}
Background: Snake bite is an important health hazard which may lead to fatality in rural areas of Bangladesh. An epidemiological study estimated the incidence of snake bite in Bangladesh about 8,000 per year with $22 \%$ mortality. In majority of cases the victims die before entrance to hospital because of their treatment seeking behavior from Ohzas. Present study is to see the clinical profile of snake bite cases admitted in Dhaka Medical College Hospital and also to find out problems in diagnosis and management and outcomes. Methods: Fifty patients of snake bites treated in Dhaka Medical College Hospital, Dhaka, Bangladesh between July 2005 and December 2006 were studied. A questionnaire, containing information on bite, physical examination and identification of snake brought was used. Results: Among the patients venomous snake was $6(50 \%)$ with cobra and $6(50 \%)$ with suspected krait bite. Males were bitten more frequently than females $42(82 \%)$ versus $9(18 \%)$. Regarding occupation, 28 (56\%) was farmer. Majority 37(74\%) came from rural areas. Highest number of bite occurred in evening 20(40\%). Most snake bite occurred during rural foot walking (30\%) followed by sleeping (14\%).Total $54 \%$ of bite occurred during outdoor activities. Most common site of bite is lower limb $35(70 \%)$. Tight tourniquet used in $45(90 \%)$ cases and in $8(16 \%)$ cases limb was immobilized. Twenty eight (56\%) of the patients received treatment from Ohzas. All venomous bites (12) presented with features of neurotoxicity with local envenoming in $6(50 \%)$ cases. In $6(50 \%)$ cases there were only neuroparalysis. Four $(33.34 \%$ of venomous snake) patients required respiratory support and $10(83 \%$ of venomous bite) patients required antivenom. There were no anaphylactic reactions and only 2 patients suffered pyrogenic reaction. The outcome was excellent with only one death and only one case of residual effects. Conclusion: To develop an appropriate prevention and control strategy, reliable and timely information has a crucial role. A functional mechanism should be developed to gather information not only about the cases and deaths but other aspects of the snakebite epidemiology.
\end{abstract}

Key words : Snakebite; reptiles.

\section{INTRODUCTION}

Snakes are reptiles present on land, in the sea, in forests, in grasslands, lakes and in deserts. Despite their sinister reputation, snakes are almost more scared of us than we are of them. Few snakes with the occasional exception of king cobras (ophiophagus hannah) or black mambas ('Dendroaspis polylepis), act aggressively towards a human without provocation.

It has been estimated that 5 million snake bites occur worldwide each year, causing about 125,000 deaths. Snake bites are more common in tropical regions and in areas that are primarily agricultural. In Bangladesh snake bite is a terrifying acute medical emergency in rural area in particular. Estimate was 4.3 bites per 100,000 populations with 2000 deaths per year following snake bite. This is known to be a health hazard for centuries which was under the per-view of traditional healers, 'Ohzas' who used to demonstrate a number of rituals for providing treatment which have been found to be useless, at times harmful ${ }^{1}$. 
Snake bite is a result of an unfortunate accidental interaction between a snake and a human victim. Most often the victim is an active poor young people who get the bite during day to day occupational activities like cultivation, fishing, plantation, wood collection, watching the crop or garden, lying in the floor or even during rural foot walks ${ }^{1}$

Among the snake families two major families of snakes account for most venomous snakes dangerous to humans. These are the elapidae and the viperidae. Among the elapidae, cobra bite usually causes neurotoxic features with local envenoming. Other elapidae like krait bites usually causes neurotoxic features without local envenoming.

Among the viperidae Russell's viper bites usually causes local envenoming with heamatological manifestations rarely with neurtoxicity (in Sri Lanka for example) whereas the green pit bites cause local envenoming with hematological toxicity. Sea snake bites usually causes myotoxicity. A victim who is very young, old, or has other diseases may not tolerate the same amount of venom as well as a healthy adult. Serious venom effects can be delayed for hours. A victim who initially appears well could still become quite sick. All victims should seek medical care without delay ${ }^{2}$.

Appropriate first aid includes immobilization of the bitten limb, non-tempering the bite site and quick referral for evaluation for envenomation. Attention of respiratory function and if needed providing support by Ambo bag while on transfer is essential as large number of snake bite have been found to die due to presumed respiratory paralysis before arrival to hospital (Hospital management includes differentiation of venomous from non venomous bite by looking for clinical criteria, bed site $20 \mathrm{~mm}$ whole blood clotting test, species identification by careful examination of brought specimen if any and if facilities available venom antigen detection in bite site, serum and urine. In Bangladesh method for detection of venom-antigen is not available for routine clinical practice. Based on clinical criteria of envenomation polyvalent anti snake venom, the specific drug for treatment of venomous snake bite is provided depending on availability ${ }^{1}$. The anti- snake venom (ASV) is not manufactured in Bangladesh, and supply is being given in government hospital which is manufactured in India in either lyophilized or serum from. The supply of ASV in public hospital is irregular and is not available in private hospitals and is not easily available in the private market as well.

Being a rural poor man's life threatening health condition, snake bite deserves special attention for saving young active earning members of the community conforming our pro-poor strategy and commitment of Millennium Development Goal. By ensuring free supply of logistics including ASV in all public hospital of the country and by having trained health professionals in all such places we can demonstrate our eagerness not to keep snake bite 'neglected disease' any more. Inability to provide such bare requisite will continue to encourage treatment seeking from 'Ohzas'.

There is scanty information about snake bite from Bangladesh and published reports are mostly from Chitagong, Khulna and Rajshahi though snake bite cases are not uncommon but there was no published report from Dhaka Medical College Hospital, the biggest tertiary care public hospital of the country except a case report ${ }^{3}$.

\section{Epidemiology of snakebite}

Snake bite remains a public health problem in many countries even though it is difficult to be precise about the actual number of cases. It is estimated that the true incidence of snake envenomation could exceed 5 million per year. About 100,000 of these develop severe sequel. The global disparity in the epidemiological data reflects variations in health reporting accuracy as well as the diversity of economic and ecological conditions ${ }^{4}$.

To complicate matters further, accurate records to determine the exact epidemiology or even mortality in snake bite cases are also generally unavailable ${ }^{5}$. Hospital records fall far short of the actual number owing to dependence on traditional healers and practitioners of witchcraft etc. It has been reported that in most developing countries, up to $80 \%$ of individuals bitten by snakes first consult traditional practitioners before visiting a medical centre $^{6}$. Owing to the delay several victims die during transit to the hospital.

There is importance of distinguishing between hazardous snakebites, which occur when humans encounter a snake accidentally and 'illegitimate' snakebites inflicted by an animal kept in captivity, or during snake handling. In industrialized countries the frequency of illegitimate snake bites is increasing while hazardous bites predominate in developing countries ${ }^{7}$.

The age and sex incidence of snake bite victims throws light on the vulnerable section of the population. While snake bite is observed in all age groups, the large majority (90\%) are in males aged 11-50 years. The predominance of male victims suggests a special risk of outdoor activity ${ }^{8}$.

The high incidence of snake bite between 0400 hours to midnight corresponds well with the period of maximum outdoor activity observed in most studies. The incidence of snake bite shows a distinct seasonal pattern closely related to rainfall and temperature which compels the reptiles to come out of their shelter'.

Most patients are unable to identify the snake species either because of ignorance or poor visibility in darkness. A large number of bites occur in fields, most individuals are unable to spot the snake due to tall grass and crops. The observation that the most frequent site of bite is the lower extremity suggests that in most cases the snake is inadvertently trodden upon.

Morbidity and mortality resulting from snake-bite envenomation also depends on the species of snake involved, since the estimated "fatal dose" of venom varies with species. Among the various species, the average yield per bite in terms of dry weight of lyophilised venom is $60 \mathrm{mg}$ for cobras, $63 \mathrm{mg}$ for Russel's viper, $20 \mathrm{mg}$ for krait and $13 \mathrm{mg}$ for saw scaled viper. The respective "fatal doses" are much smaller viz $12 \mathrm{mg}$, $15 \mathrm{mg}, 6 \mathrm{mg}$ and $8 \mathrm{mg}$ because every bite does not result in complete envenomation. Epidemics of snake bite following floods owing to human and snake populations getting concentrated together have been noted in Pakistan, India and Bangladesh. 


\section{Epidemiology of snakebite in Bangladesh}

Information about snake bite was scanty in Bangladesh until recently. An epidemiological study estimated the incidence of snake bite in Bangladesh about 8,000 per year with $22 \%$ mortality ${ }^{10}$. Azhar et al (1994) and Faiz et al (1999) reported 74 and 179 (131 non-venomous and 48 venomous bite) cases from Rajshahi and Chittagong Medical College Hospitals respectively ${ }^{11,12}$. A survey of $10 \%$ of the country in 1988-89 revealed 764 bites with 168 deaths in one year. Cobra bites (345 of all bites) caused a case fatality of $40 \%$. The incidence was high $(60 \%)$ in between July and October. The incidence was higher at the age range between 20 and 30 (30\%). Only 7 $\%$ of the total Cases were hospitalized and $90 \%$ were sent to the traditional healers ("Ozhas"). The Common sites of bite are the legs $(71.6 \%)$ and hands $(24.3 \%)$. Ninety-nine percent incidents are recorded from rural areas. Most incidences $(50.5 \%)$ occurred at night. Farmers $(38.4 \%)$ who work bare foot in the field and interact directly with the snakes are affected mostly. During the monsoon, the incidence is high; due to rainfall, the snakes come out of their shelters. Biting occurs mostly when the people are at work (31\%). However, bite are fairly common (23.3\%) when the victims are at sleep, since in Bangladesh most of the houses are not brick built and the snakes sometimes live in the holes of the earthen floors moreover most of the houses in the villages have homestead forest. So incidence is high (58\%) when people are at home. To go to the toilet and for other domestic purposes people often come out of their houses. In the village, people store grains including paddy in their bedroom and the houses are built of mud which give shelter to the snakes.

A snake bite clinic was established in October 1993 in Chittagong Medical College hospital to document all the victim of bite admitted in this hospital. In ten years total 1666 snake bite cases were admitted and from them only 8 people died. The species involved in most of the cases were nonvenomous $(61.5 \%)$.Among the venomous species majority were cobra(29.6\%), krait(4.9\%), green snake (62.5\%), few sea snakes and some may be Russel, viper.Other facility based reports regarding fatalities are low 2/74 in Rajshahi. Most of the patients were farmer, house wife, student, laborer. Relatively younger people of poor socioeconomic condition were common victims. People usually lose valuable time before reaching the hospital while seeking treatment from traditional healers. Data showed that around 40 people died while enrooted to hospital. A four year survey (1999-2002) of 13 thana health complexes of Chittagong revealed 421 snake bite cases. Among them in Patiya thana health complex highest number of cases (151) admitted, however highest number of deaths occurred in Baskhali(5/20).

Over a period of one year, 61 patients with 9 venomous bite were treated in Dhaka Medical College hospital in 2004.12 of them required $\mathrm{ASV}, 04$ of them required assisted ventilation, three victims of venomous snake bite died two of whom were brought dead. During the flood of 2004 DGHS recorded 99 death following snake bite through the existing surveillance system $^{13}$.

\section{Medically important snake of Bangladesh}

Medically importance snakes of Bangladesh can be placed into five groups:

\section{Group-I: Cobra (Zoura)}

1. Naja kaouthia, monocellate cobra, gokhra, gokhur, jati/jat shap, dashla, gohma.

Distributed in all civil divisions of Bangladesh

2. Naja naja, binocellate cobra, spectacled cobra, gokhra, gokhur, khaiya gokhra.

Distributed in all civil divisions of Bangladesh, but more common in west of Jamuna river.

3. Ophiophagus hannah, kingcobra, rajgokhra, shankhachur, padmagokhra, phanos

Distributed in Sylhet, Chittagong, Khula and Barisal divisions.

Group-LI: Krait- Common two are

4. Bungarus caeruleus, common krait, kal kewtey, kalas, maicha-alad. Distributed in all divisions of Bangladesh.

5. Bungarus fasciatus, banded krait, sankhini, shakini, mama-bhagna.

Distributed in all divisions of Bangladesh, but more in Chittagong division and rarely is Rajshahi.

Group-III: Russell's Viper

6. Daboia russelli, Chandrabora.

Distributed mainly in Rajshahi division and may be found in Chittagong division.

Group-IV: Green pit viper

7. Ovophis (Trimeresurus) spp. green pit viper, green snake, bansh bora, gal tawa, sabuj bora.

Distributed in Sylhet, Chittagong, Khulna and Barisal division

Group-V: Sea snakes

8. Enhydrina schistosa, hook nosed sea snakes, samudrik shap.

Distributed in sea and coastal saline water of Bangladesh.

9. Hydrophis spp, Microcephalis spp, Laticauda spp, sea snakes, samudrik shap. Distributed in sea and coastal saline water of Bangladesh.

\section{MATERIALS \& METHODS}

It was a descriptive, prospective study, which was carried out in medicine indoor department of Dhaka Medical College hospital on consecutive 50 patients who were found to be present with snake bite. Detail history, through clinical examination will be performed to elicit the type of snake bite, to know about prehospital treatment received and to find out problems in diagnosis and management.

\section{Objectives}

In majority of cases the victims die before entrance to hospital because of their treatment seeking behavior from Ohzas. However trend is now going to change. In this study i have taken hospitalized patients admitted with complains of snake bite for following objectives. 
Specific

- To see the clinical profile of snake bite cases admitted in $\mathrm{DMCH}$

\section{General}

- To see the demographic profile- age sex, occupation, time of bite site, site of bite, pre hospital treatment, hospital treatment.

- To find out problems in diagnosis and management.

- To see the outcome of the cases of snake bite.

\section{RESULTS}

Thirty eight cases were with nonvenomous bite and 12 with venomous bite. Among the venomous bites 6 were by suspected cobra and 6 were by suspected krait. All patients with venomous bites presented with features of neurotoxicity with or without local envenoming. Among 12 venomous bites, 10 were managed by ASV and two were improved by supportive treatment.

The age of the victims varies from 3.5 years to 60 years with a mean of 38.5 years (Table 1 ).

Table 1: Age distribution of the patients $(n=50)$

\begin{tabular}{lcc} 
Age (year) & Frequency & Percent \\
$0-10$ & 4 & 8.0 \\
$11-20$ & 21 & 42.0 \\
$21-30$ & 12 & 24.0 \\
$31-40$ & 6 & 12.0 \\
$41-50$ & 6 & 12.0 \\
$51-60$ & 1 & 2.0 \\
Total & 50 & 100.0 \\
\hline
\end{tabular}

Out of 50 enrolled patients males $41(82 \%)$ were predominant, $74 \%$ were from rural areas and majority were farmers (Table 2). Table 3, 4 and 5 depict the time, circumstances and sites of snakebite.

Table 2: Occupation of the patients $(n=50)$

\begin{tabular}{lcc} 
Occupation & Frequency & Percent \\
Farmer, Labour & 18 & 36.0 \\
Farmer, Land owner & 10 & 20.0 \\
Housewife & 7 & 14.0 \\
Private business & 4 & 8.0 \\
Student & 4 & 8.0 \\
Govt. employee & 4 & 8.0 \\
Others & 2 & 4.0 \\
Snake charmer & 1 & 2.0 \\
Total & 50 & 100.0 \\
\hline
\end{tabular}

Table 3: Time of Bite $(\mathrm{n}=50)$

\begin{tabular}{lcc} 
Time & Frequency & Percent \\
Morning & 17 & 34.0 \\
Evening & 20 & 40.0 \\
Night & 13 & 26.0 \\
Total & 50 & 100.0 \\
\hline
\end{tabular}

Table 4: Circumstances of snake bite $(n=50)$

\begin{tabular}{lcc} 
Circumstances & Frequency & Percent \\
Rural foot walking & 15 & 30.0 \\
Lying in the floor & 7 & 14.0 \\
Cultivation & 4 & 8.0 \\
Fishing & 3 & 6.0 \\
Wood collection & 3 & 6.0 \\
Plantation & 1 & 2.0 \\
snake charming & 1 & 2.0 \\
Others & 16 & 32.0 \\
Total & 50 & 100.0 \\
\hline
\end{tabular}

Table 5: Site of bite $(\mathrm{n}=50)$

\begin{tabular}{lcc} 
& Frequency & Percent \\
Sole of left foot & 4 & 8.0 \\
Dorsum of left foot & 11 & 22.0 \\
Sole of right foot & 4 & 8.0 \\
Dorsum of right foot & 11 & 22.0 \\
Left leg & 5 & 10.0 \\
Left hand & 3 & 6.0 \\
Right hand & 11 & 22.0 \\
Left forearm & 1 & 2.0 \\
Total & 50 & 100.0 \\
\hline
\end{tabular}

Application of tourniquet is a common pre-hospital treatment practice after snakebite (Table 6).

Table 6: Pre-hospital treatments taken by the victims

\begin{tabular}{lcc} 
Pre-hospital treatment & Frequency & Percentage \\
Tourniquet given & 45 & 90.0 \\
Bitten limb immobilized & 8 & 16.0 \\
Treatment from ohzas & 28 & 56.0 \\
Multiple incision given by Ohzas & 12 & 24.0 \\
Suction by mouth & 4 & 8.0 \\
Cauterization by chemicals & 1 & 2.0 \\
Ingestion of oil, ghee, herbal product & 4 & 8.0 \\
Visit any GP doctor or Clinic & 31 & 62.0 \\
\hline
\end{tabular}

Among the venomous snakebite patients, all 12 presented with neurological involvement. In one patient there was nonspecific ST-T wave change which disappeared after 5 days (Table 7). 
Table 7: Complications due to snake bite $(\mathrm{n}=12)$

\begin{tabular}{lcc} 
Complications & Frequency & Percentage \\
Local envenomation & 6 & 50.0 \\
Neurological involvement & 12 & 100.0 \\
Haemostatic abnormality & 0 & 0 \\
Cardiovascular abnormality & 1 & 8.33 \\
Renal failure & 0 & 0 \\
Haemoglobin-myoglobinuria & 0 & 0 \\
\hline
\end{tabular}

Among 12 venomous snake bites, 10 need antivenom of which 8 patients received single dose, 1 received 2 doses and another received 4 doses.

Forty seven victims were completely recovered and only one died after 10 days.

\section{DISCUSSION}

In a few occasions venomous snakes were identified by the specimens brought with victims; however in most instances they were suspected on history and physical findings. The selection was based on history of snake bite and willing to give witnessed written consent.

The mean age of the victims in our series was 38.5 years and two thirds were below 30 years. This observation is comparable with another hospital based study conducted in northern Bangladesh on 68 cases where the mean age was 26.7 years $^{13}$. Study conducted in Chittagong Medical College Hospital found mean age of $29.6 \%{ }^{17}$. Study in Nepal reported $85 \%$ victims were less than 45 years old ${ }^{14}$. Male predominance in our series is similar to other studies in Chittagong, Rajshahi and Khulna. ${ }^{13,15-16}$. Majority of our victims were farmers which corresponds to a long-term study in Pune, India ${ }^{17}$.

Highest number of bites occurred during daytime in our study which is similar to other studies in Bangladesh. ${ }^{12-13,17}$ As most of the snakebites occurred by accidental interaction so occupational activities by rural people during the day time is the reason of increased number of bites. However a Sri Lankan study reveals midnight predominance ${ }^{18}$.

Dead snakes were brought by $10(20 \%)$ of the victims or their attendants. Among them 1 was krait, 2 were cobras and other species could not be identified but seems to be nonpoisonous as per clinical scenario. In the absence of facilities of ELISA technique of snake identification, the brought specimen of snake can be preserved for identification and demonstration. However people need to be informed about the usefulness of snake in ecological balance and should not be allowed or encouraged to kill snakes for species identification. Lower limb is the most common site of bite in this study which is supported by other studies in home and abroad ${ }^{13,16,17,19}$.
Most of the snake bite happened between May to October in our series as well as in other studies. ${ }^{15-16} \mathrm{High}$ incidence of snake bite is not unexpected during flooding and cyclone in Bangladesh.

A significant number of patients used tight tourniquet which is far from scientific and safety. It is recommended that application of tourniquet over a single bone for a brief period could be used as a first aid measure to prevent and delay the spread of venom in the systemic circulation. Tun Pe et al. demonstrated that application of local pressure by compression pad and immobilization of the limb could retard the venom antigenaemia in 13 of the 15 cases $^{20}$. A large number of victims received pre-hospital treatment from Ohzas (traditional healers). The mode of treatment by Ohzas were in the form of multiple incisions, cauterization by chemicals, suction by mouth, ingestion of oil, ghee, herbal products.

Only 4 patients required artificial respiratory support due to respiratory muscle paralysis. The duration of mechanical ventilation in snake bite victims is usually short since neuroparalysis reverses quickly with prompt administration of ASV.

All patients were treated with recommended dose and route of antivenom following the guideline of W.H.O/S.E.A.R.O. The outcome was excellent with only one death and only one case of residual effects. The case of residual effects develop pressure sore and need surgical debridment and toileting. A study in northern Bangladesh showed 7 deaths(26\%) treated with antisnakevenom in a dose of $20 \mathrm{ml}$ to $40 \mathrm{ml}$. Study of Khulna Medical College shows that out of 108 venomous snake bite cases 101(93.52\%) recovered completely and $7(6.66 \%)$ died after admission and 60(55.5\%) cases recovered with $20-30 \mathrm{ml}(2-3$ vials $)$ of polyvalent antisnakevenom ${ }^{16}$. A prospective study of hospital practice in the Gampaha district ,Sri Lanka including 466 patients of whom 184 patients were venomous bite showed only 2 patients were dead $(0.43 \%)$ where at least 10 vials $(100 \mathrm{ml})$ of antivenom was initially given $^{21}$.

The outcome of neurotoxic snake bite patients in this series was excellent. Although six patients were critical during presentation prompt treatment with antivenom, auxiliary treatment and quick management of pyrogenic reaction saved these valuable lives. So it is justifiable to use antivenom whenever indicated without fear and adverse reactions are quite easy to manage with effective available drugs. Evidence from this study certainly is encouraging for physicians to use antivenom.

\section{CONCLUSION}

Appropriate training on the management of snakebites should be provided to health personnel, including PHCs. An adequate supply of ASV and other medicines should be made available to all the treatment facilities where snakebites are a problem.

\section{DISCLOSURE}

All the authors declared no competing interest. 


\section{REFERENCES}

1. Faiz MA et al. Snake bite in Bangladesh. The Orion 2006 Jan-Aprl;23:322.

2. Faiz MA et al. National guide line for management of snake bite Bangladesh 2000.

3. S Ahmed, J Chowdhury, N Amin, MAH Mollah, M A Faiz, H Hasan et al. Near fatal snake bite in a girl: A journey through ICU.DS(Child) H J 2005;21(1): 36-38.

4. Sawai Y. Study on deaths due to snakebite in Anuradhapura District, Sri Lanka. Snake 1984;16:7-15.

5. Aung-Khin M. The problem of snake bites in Burma. Snake 1980;12:125-127.

6. Naing S. Clinical profile of viper bite cases. Divisional Hospital, Magwe (1981-82). Burmese Medical Journal 1985;31:195203.

7. Joshi DD, Toriba N, Kawamura Y, Hayashi Y. Snake bites in Terai region of Nepal. In: International conference on Environment of Occurrence of Snake Bites and their Medical Treatment and Prophylaxis. Maebashi City, Japan 30 August-1Sept'97 [Abstracts] : p 7.

8. World Health Organisation. Zoonotic disease control. Baseline epidemiological study on snake-bite treatment and management. Weekly Epidemiolog Rev. 1987;42:319-320.

9. Hansdak SG, Lallar KS, Pokharel P, Shyangwa P, Karki P, Koirala S. A clinico-epidemiological study of snake bite in Nepal. Tropical Doctor 1998;28:223-226.

10. Hug F , Islam M A ET AL, Epidemiology of snake bite in Bangladesh, Bangladesh J Zool 1995;23:61-64.

11. Azhar MA, Chowdhury MAJ,Ahsan HAMM,Rafiqueddin AKM.Experience with snake bite cases in medical indoor. TAJ (Rajshahi) 1994;7(1):47.

12. Faiz MA et al .Snake bite in Chittagong and Cox`s bazar a hospital based study. Bangladesh J Medicine (1997);8:52-57.

13. Islam Q T, Azhar M A, Ekram A R M S, Snake bite in the northern Bangladesh: a hospital based study of 68 cases, TAJ1999; 12:135-138

14. Devkota U N,Steinmann JP, Shah LN, Snake bite in Nepal- A study from Sihara district.J Nepal Med Assoc 2000;39:203-209.

15. Faiz M A et al. Bangladesh J Medicine(1997);8:52-57.

16. Abu Baker,Nazmul Ahasan,Manwar Ahsan. Snake bite in Bangladesh.Pak Armed Forces Med J Mar 2006;56(1):68-72.

17. M A Faiz ,M R Rahaman, A Hossain, E B Younus, J C Das, S A Karim, et al.A Hospital Based Study of Snake Bite in Chittagong Medical College.J.Bang. Col. Phys. Surg.(1995);13:3-8.

18. S A M Kularatne. Common krait (Bungarus caeruleus) bite in Anuradhapura, Sri Lanka: a prospective clinical study,1996-98. Postgrad Med J 2002;78:276-280.

19. Chen JC,Liaw SJ,Bullard MJ, Chia TF. Treatment of poisonous snake bite in Northern Taiwan.J Forms Med Assoc(China)2000;99(2):135-9.

20. Hasan SM,Azahar Ali,Jalil MA,Faiz MA. The impact of snake bite on house hold economy in Bangladesh.In press.

21. Seneviratne SL, Guantilke S B,De Silva H J.Use of antivenom serum in snake bite.a prospective study of hospital practice in Gampaha district,Ceylon Medical Journal,2000;45:65-68. 